\title{
El fundamentalismo religioso y los derechos humanos en América Latina
}

\section{Religious Fundamentalism and Human Rights in Latin America}

\section{O fundamentalismo religioso e direitos humanas na América Latina}

Abner Barrera-Rivera

Académico investigador

Instituto de Estudios Latinoamericanos

Universidad Nacional, Costa Rica

Recibido: 6/03/2019

Aceptado: 5/04/2019

DOI: https: //doi.org/10.15359/tdna.35-65.12

\section{Resumen}

El presente artículo aborda el tema de la relación entre la religión y la política a partir del fenómeno fundamentalista neopentecostal que en los últimas décadas ha venido teniendo protagonismo en diferentes países de América Latina. Se busca mostrar cómo este fenómeno se ha venido expandiendo, con una agenda moral que niega, restringe y

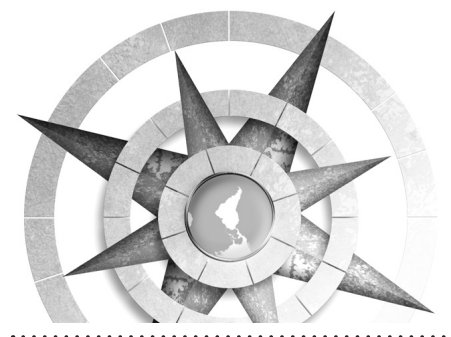


Keywords: Neopentecostal movement, human rights, diversity, Costa Rica, Latin America

\section{Resumo}

Neste artigo aborda-se a relação entre religião e política a partir do fenômeno neopentecostal fundamentalista que, nas últimas décadas, tem desempenhado um papel de liderança em diferentes países da América Latina. Procura mostrar como esse fenômeno vem se expandindo, com uma agenda moral que nega, restringe e viola os direitos humanos das chamadas populações "minoritárias".

Palavras chave: Movimento neopentecostal, direitos humanos, diversidade, Costa Rica, América Latina

El presente artículo aborda el tema de la relación entre la religión y la política a partir del fenómeno fundamentalista neopentecostal que en los últimas décadas ha venido teniendo protagonismo en diferentes países de América Latina. Se busca mostrar cómo este fenómeno socioreligioso, sociocultural, y sociopolítico se ha venido expandiendo, con una agenda moral que niega, restringe y viola los derechos humanos de poblaciones denominadas "minoritarias". Asimismo, ha tenido la capacidad de movilizar las conciencias (algunos dirían cauterizar las conciencias, porque el fundamentalismo no genera pensamiento ni reflexión crítica). Por razones obvias, no es posible abordar aquí, lo que sucede en todos los países del continente, sin embargo, al enfocamos en el caso de Costa Rica teniendo en cuenta lo que está sucediendo en el contexto latinoamericano.

En las elecciones para presidente y legisladores del 4 de febrero de 2018, Costa Rica vivió por primera vez la presencia significativa de los sectores religiosos más conservadores en la política; estos nuevos actores modificaron de manera sustancial la agenda de discusión política, la adhesión a los partidos tradicionales y la convivencia social; la sociedad se enfrentó como nunca antes, a una situación que poco o nada tenía ver con su tradición pacifista y respetuosa de los derechos humanos. En todas partes del país (con repercusiones internacionales) estuvo presente la llamada agenda moral con temas políticos-religiosos asumida por el señor Fabricio Alvarado, candidato neopentecostal del Partido Renovación Costarricense (PRC).

Para realizar esta pesquisa, el acceso a las fuentes fue determinante; en lo que respecta a la información acerca del surgimiento del fundamentalismo religioso, recurrimos a investigaciones de algunos escritores protestantes y ecuménicos; sobre los datos sobre la conformación y participación de 
los partidos políticos confesionales en América Latina y el mensaje que portan, indagamos en los artículos de revistas digitales y periódicos de distintos países (la mayoría de ellos es de reciente fecha de publicación) y para el análisis crítico y propositivo del fenómeno en cuestión, nos valimos de algunos autores representativos de las teorías críticas de los derechos humanos y las epistemologías del sur.

\section{El fundamentalismo religioso y la política}

Los inicios del fundamentalismo religioso se remontan a la segunda década del siglo XX en los Estados Unidos de América, específicamente entre los sectores pentecostales, pertenecientes a los sectores socioeconómicos más pudientes.

La palabra fundamentalismo se usó como un arma de combate contra un fenómeno abierto y renovador del protestantismo liberal dentro de Estados Unidos; liberal desde el punto de vista político y cultural, y portador de un humanismo secular. Los fundamentalistas eran los que se oponían al movimiento teológico liberal y a las ideas evolucionistas, que devino más tarde en prácticas de intolerancia e irracionalidad hacia los que no se afiliaban incondicionalmente con ellos (Tamayo, 2009, p.76); se caracterizaban por hacer ataques basados en prejuicios y odios hacia todo aquel que pensara mínimamente diferente a ellos.
Desde sus inicios se caracterizó por hacer una lectura literal de la Biblia, y llevar sus planteamientos al campo de la ciencia, y estuvo ligado a lo que se denominó "la iglesia electrónica" que contaba con sus telepredicadores (Assmann, 1988). Poseían una enorme industria cultural y religiosa que producía discos, audiovisuales, libros, revistas, etc.; constituyéndose eso en un negocio a partir de la fe que predicaban. En 1929, con la crisis de la Gran Depresión, renunciaron a cualquier interpretación política y económica de los hechos y sostuvieron que la crisis era resultado de la perversión de la sociedad norteamericana y, el anuncio de la llegada del anticristo; poco a poco fueron ocupando espacios políticos.

El fundamentalismo se distingue por lo siguiente: 1) creencia en un Dios, que es personal y universal, que incluye a los creyentes y no creyentes; y tiene un proyecto de salvación para toda la humanidad; 2) ese Dios es único y verdadero, y transmite su voluntad a un profeta, a quien le comunica su voluntad; ese profeta se considera representante auténtico de Dios y de su mensaje; 3) ese mensaje que Dios le revela se pone por escrito en un texto sagrado (en el caso de los cristianos es la Biblia), y esa palabra es verdad, para cualquier circunstancia, contexto, tiempo y en todos los ámbitos (religioso, social, político, económico, etc.); 4) la interpretación del texto sagrado es literal en el sentido 
moral y jurídico, ese texto es considerado verdadero en todos los campos y en todos los tiempos (de ahí provienen los conflictos entre la fe y la ciencia); y los imperativos sagrados trascienden el lugar y contexto, no importa las circunstancias en las que se encuentre la persona; 5) la interpretación del texto sagrado es realizada única y exclusivamente por la autoridad competente (en un principio llamados pastores y ahora profetas).

Un ejemplo de la aplicación de la literalidad del texto sagrado lo encontramos en todas las situaciones que tienen que ver con la mujer; cuando un texto se refiere a la mujer y lo hace discriminadamente, los fundamentalistas dicen que ese texto es verdadero y puede ser entendido literalmente. Lo mismo hacen con los textos sobre el matrimonio entre varón y mujer, para justificar el matrimonio heterosexual y condenar el matrimonio homosexual o igualitario. Otro caso del literalidad fundamentalista es lo referente a los textos que tienen que ver con la homosexualidad y que usan para condenar, radicalmente, a las personas homosexuales.

En la década de 1970, estos sectores conservadores se aliaron al ala derecha del proyecto político del Partido Republicano y realizaron campañas agresivas contra el aborto, la homosexualidad y apoyaron las guerras de los Estados
Unidos en Centroamérica, Panamá y el Golfo Pérsico (Piedra, 2006, pp. 271274). Se dio así una complicidad entre los fundamentalistas de la mayoría moral y el republicanismo de los políticos de los Estados Unidos.

A partir de los años de 1980 las iglesias fundamentalistas se hicieron presente en el protestantismo latinoamericano, marcando gran diferencia con el resto de las iglesias evangélicas. Según Míguez (1995, p. 52). estos sectores tuvieron influencia negativa en el protestantismo, porque lo vincularon a los peores rasgos de la ideología y la política de los Estados Unidos, y les hicieron asumir como propias las campañas ideológicas reaccionarias de "la nueva derecha religiosa" de los Estados Unidos y apoyaron los "regímenes de seguridad" y las políticas represivas que por varias décadas acompañaron esa política.

Una vez que el pentecostalismo fundamentalista -conocido también como neopentecostalismo- llegó a América Latina, se extendió y tuvo un gran crecimiento en las últimas décadas. Pronto estuvo presente en el escenario público, traspasando los límites tradicionales de sus templos. Su presencia en la política se realizó a través de los partidos confesionales los cuales izaron como mensajes de lucha, temas concernientes a los derechos humanos, con una visión reduccionista desde una moralidad religiosa. Pero 
el accionar y participación de ellos en la vida pública no se desarrolló a espaldas de los acontecimientos políticos, sociales, económicos y culturales que vivieron nuestros países; más bien, se desplegó emparentado con el conservadorismo político y el neoliberalismo económico.

\section{El neopentecostalismo en América Latina}

La contienda electoral en Costa Rica el 2018 fue sui géneris, porque la participación de sectores neopentecostales alrededor del candidato Fabricio Alvarado ocupó un lugar central por espacio de cinco meses. Este protagonismo se explica mejor si se toma en cuenta el contexto latinoamericano del fenómeno neopentecostal en la política.

En América Latina el crecimiento de estas iglesias ha sido vasto en las últimas décadas; los datos de Brasil, México y Argentina, los tres países más grandes de la región, lo demuestran:

1) En Brasil, la cantidad de personas que dicen pertenecer a uno de los grupos pentecostales está en constante crecimiento: 3,9 millones en 1980, 8,8 millones en 1991 y 18 millones en 2000. Mientras la tasa de variación media anual de los pentecostales observada de 1991 a 2000 crece un $8,3 \%$, la población total solo aumenta un $2 \%$ en ese mismo período (Romero, 2003, p. 39);
2) En México, país de mayoría católica, en las últimas décadas ha habido un descenso constante de esta religión, mientras que ha habido un crecimiento exponencial de religiones no católicas, particularmente las iglesias evangélicas y pentecostales (de la Torre y Gutiérrez, 2007, p. 7); y

3) En Argentina pocos años después de la dictadura militar (1976-1983) hubo un gran avance del pentecostalismo; estas iglesias llenaron estadios y sus campañas evangelizadoras atrajeron una multitud de seguidores. Según algunas encuestas de inicios de los años noventa muestran que, para esa fecha, los protestantes en general se aproximaban al 10\% de la población, lo que evidencia su incremento comparado con el $2.6 \%$ que correspondía a 1960 (Míguez, 2001, p. 23) (Mallimaci, 2013).

La participación de pastores neopentecostales en los procesos electorales también aumentó en todo estos años y tiene relación con la creciente ofensiva conservadora en América Latina. Incursionaron con candidaturas propias o en alianzas con otros partidos y recurrieron al poder simbólico de lo religioso relacionando las creencias de la fe con la elección de ofertas políticas (sociales, económicas y culturales) buscando encausar la desesperanza social de las personas dentro y fuera de la iglesia (en su mayoría son personas empobrecidas) y su hartazgo con los partidos 
políticos que por varias décadas no les han dado respuesta a sus necesidades. Así fusionaron el poder de convicción y creencia de la predestinación religiosa de la salvación pos-existencial al discurso político de un porvenir moralizador y bíblico como redención terrenal (Calderón, 2017).

En América Latina de cada cinco personas una es evangélica y en algunos países es el doble (en Honduras y Guatemala, el fenómeno se acentúa y los evangélicos igualan o superan en porcentaje a los católicos) (Lissardy, 2018). A partir de los años ochenta estas iglesias aumentaron exponencialmente; se estima que en la actualidad podrían estar congregando al 20\% de los latinoamericanos (Sánchez, 2018). El número de evangélicos en el mundo es de 565 millones, y 107 millones se encuentran en América Latina y el Caribe, y existen más de 19 mil iglesias neopentecostales en la región (Saccone, 2016). Estas cifras indican un desplazamiento de la Iglesia Católica, otrora institución mediadora del poder simbólico de la fe religiosa de los latinoamericanos.

El quehacer de los neopentecostales en la vida social y política, no solo es diferente a la presencia histórica que tuvieron en América Latina las iglesias pentecostales, sino también las otras iglesias cristianas (luteranas, calvinistas, anglicanas, metodistas, bautistas, presbiterianas, etcétera). Fue un sector reducido de esas iglesias, el que participó en la política electoral, y no se interesaron por tratar temas específicos de derechos humanos, como ahora lo hacen los partidos confesionales.

En los años de 1980 en varios países se crearon pequeños partidos, donde sus líderes evangélicos tuvieron algún tipo de apoyo de sus iglesias y lograban colocar algunos de sus miembros en los poderes del Estado. Por ejemplo, en Guatemala en 1982 obtuvo la presidencia el evangélico José Efraín Ríos Montt miembro de la Iglesia Verbo, en Venezuela, en 1987, el presbiteriano Godofredo Marín, fue candidato a la presidencia por el partido Organización Renovadora Auténtica (ORA); en Brasil en 1989 el evangélico Iris Machado Rezende, fue candidato a las elecciones primarias del Partido Movimiento Democrático Brasileiro (PMDB) para la selección del candidato a las presidenciales de ese año (Parrode, 2014); en Perú, en 1990 el pastor bautista Carlos García, se convirtió en vicepresidente (1991-1992) postulando con el partido Cambio 90 de Alberto Fujimori (en esas filas hubo pastores y líderes evangélicos elegidos como diputados y senadores) (López, 2004); en Guatemala (1991-1993), Jorge Serrano Elías y Gustavo Espina Salguero, ambos evangélicos, fueron elegidos presidente y vicepresidente respectivamente, postulados por el Movimiento de Acción Solidaria (MAS); en Nicaragua en 1996 el pentecostal Guillermo Osorno de Camino Cristiano Nicaragüense (CCN), fue 
candidato presidencial; y en Costa Rica en 1998, el evangélico Sherman Tilomas del Partido Renovación Costarricense (PRC), postuló a la presidencia. Estos son algunos ejemplos de la participación de los evangélicos en la política durante esos años, no todos los que fueron candidatos lograron ser elegidos.

A diferencia de lo sucedido en esas décadas, en años recientes el neopentecostalismo incursionó en la política electoral de forma planificada y organizada -con recursos humanos, materiales, financieros, logísticos, mediáticos y tecnológicos propios- a través de partidos confesionales, y logró en muchos casos que, sus candidatos fueran elegidos en algunos poderes del Estado. Pero independientemente de los resultados electorales, el neopentecostalismo se convirtió en este tiempo en un sujeto social que le ha dado una nueva configuración a la política en América Latina (Bastian, 1999). Se ha constituido en una fuerza política muchas veces decisiva en los asuntos públicos, entre otras razones, por las siguientes:

a) por su capacidad de determinar quiénes serán las autoridades elegidas,

b) qué rumbo tendrá un plebiscito o referendo,

c) cuáles serán las políticas públicas respecto a temas vitales;

d) qué derechos deberán ser reconocidos y cuáles postergados o negados; e) qué personajes políticos serán legitimados, protegidos o juzgados, dependiendo de su posición política-ideológica (y quienes serán adversados); y

f) cuál deberá ser el modelo económico, social y político de un país, etc.. Son una fuerza electoral que los otros partidos no ignoran como contrincante o como aliado.

En el 2000 en Colombia se creó el Movimiento Independiente de Renovación Absoluta (MIRA), expresión política de la Iglesia de Dios Ministerial de Jesucristo Internacional, que obtuvo representación en distintos espacios de poder público; y en el 2016 fue uno de los partidos confesionales con mejores resultados electorales en las últimas décadas en América Latina.

En el 2014, a dos meses para las elecciones en Brasil, la candidata presidencial, Dilma Rousseff del Partido de los Trabajadores (PT), conocida por su pasado guerrillero y declarada agnóstica, asistió al culto evangélico de casi tres horas a una de las iglesias más grandes de Sao Paulo, en la inauguración del Templo de Salomón, construido en el centro de la mayor ciudad del país. Al mismo acto asistió el entonces vicepresidente y luego presidente Michel Temer, los ministros, el gobernador y el alcalde de São Paulo, y los miembros más importantes del Congreso Nacional. El templo que se inauguró es una megaiglesia de 
100.000 metros cuadrados con capacidad para 10.000 personas. Ese proyecto fue planeado por el obispo Edir Macedo, líder de la Iglesia Universal del Reino de Dios (IURD), principal expresión de las iglesias del sector evangélico (Bedinelli, Marcos, y Lafuente, 2018).

En el 2015 en Guatemala fue elegido presidente el evangélico Jimmy Morales, con el $62 \%$ de apoyo. Este mismo año (2015) en Chile se creó el Movimiento Evangélicos en Acción (MEA) con el propósito de participar activamente en la política nacional.

En el 2017 en Brasil fue elegido alcalde de Río de Janeiro el obispo Marcelo Crivella, miembro de la denominación neopentecostal de la IURD, y hubo más de 90 congresistas brasileños que, aunque pertenecían a distintas iglesias evangélicas, actuaban muchas veces como un bloque; ellos participaron en la destitución de Dilma Rousseff, porque votaron unidos por su expulsión del poder (Vargas, 2018).

A semejanza de Brasil, también en México y Colombia, los candidatos presidenciales -de derecha o izquierda-, hicieron alianzas con organizaciones evangélicas, tratando de garantizar el apoyo de los feligreses. En México, Andrés Manuel López Obrador, un político de izquierda, del Movimiento de Regeneración Nacional (MORENA) se unió con el Partido Encuentro Social (PES) agrupación ultraconservadora. El
PES apoyó las manifestaciones del Frente Nacional por la Familia de 2016, y estimuló en congresos locales legislaciones anti-aborto y discriminatorias de la comunidad LGBT con modificaciones "mínimas" y definiciones legales, como la "protección de la vida desde la fecundación" o que el matrimonio "se compone de hombre y mujer” (Plumas, 2017).

En Colombia, después del Plebiscito de 2016, donde el voto de los evangélicos fue determinante para la victoria del "NO" (rechazaron los acuerdos de paz alcanzados por el gobierno con la guerrilla de las Fuerzas Armadas Revolucionarias de Colombia (FARC), todos los candidatos a la presidencia trataron de construir relaciones y alianzas con los líderes evangélicos buscando el respaldo de las iglesias. Si bien éstos no decidieron apoyar en un solo bloque y a un único candidato, las iglesias más grandes como la Misión Carismática Internacional cuyo dirigente César Castellanos, es el pastor incondicional del expresidente Álvaro Uribe Vélez, marcaron la diferencia al respaldar a Iván Duque candidato del partido Centro Democrático, que estuvo siempre primero en las encuestas y ganó las elecciones en junio de 2018.

Para los comicios del 20 de mayo de 2018 en Venezuela, el pastor evangélico Javier Bertucci, de la iglesia Maranatha, fue uno de los candidatos presidenciales, postuló por el partido Esperanza por el Cambio (EPC). 
Otro caso donde los políticos abrazaron las filas evangélicas, para lograr apoyo hacia la presidencia es el de Jair Bolsonaro, político de extrema derecha, militar de la reserva que defiende la tortura y el derecho de portar armas; fue bautizado por un pastor, en 2016, en aguas del río Jordán, en Israel (Bedinelli, Marcos, y Lafuente, 2018). En las elecciones de octubre de 2018, resultó en primer lugar, y tuvo amplio apoyo de los evangélicos. Bolsonaro se declaró machista, racista y homófobo; algunas de sus frases de campaña fueron: "Sería incapaz de amar a un hijo homosexual. Prefiero que un hijo mío se muera en un accidente a que aparezca con un bigotudo por ahí"; "El gran error de la dictadura fue torturar y no matar"; "Mis hijos nunca tendrán una novia negra porque han sido bien educados" (Royo, 2018). Con el resultado de la primera vuelta, impulsó el Congreso más conservador desde el fin de la dictadura (1965-1985). De los 513 asientos en la Cámara de Diputados, 301 están en manos de parlamentarios de derecha, 63 más que en la última elección (Della, 2018), y los evangélicos consiguieron 84 escaños en esa Cámara (Saccone, 2018). Para la segunda vuelta, donde Bolsonaro resultó vencedor, contó con el apoyo de más del 60\% de los evangélicos (Watson, 2018).

\section{El neopentecostalismo en la política costarricense}

En cuanto al contexto nacional, Costa Rica, un país con cinco millones de habitantes, cuyo nivel educativo está entre los mejores de América Latina, en el pasado reciente observaba de lejos y "desde arriba" lo que sucedía en países como Guatemala, Brasil, Perú, Colombia o Chile, donde aparecían candidatos religiosos a la presidencia, que proponían en sus campañas electorales, con total libertad, limitar derechos humanos a mujeres, indígenas, personas LGTBI, etc. El imaginario social en general creía que esos discursos moralistas políticos-religiosos, sólo sucedían en países con democracias frágiles o inestables, pero no en países como Costa Rica, con una larga y estable democracia. Pero era una falacia.

Para las elecciones de 2018, hubo trece candidatos a la presidencia. En diciembre de 2017 -a dos meses de las votaciones-, Fabricio Alvarado cantante (salmista) y predicador neopentecostal, candidato del PRC, apenas tenía el 3\% de respaldo; ya para el 26 de enero había subido a $16,9 \%$. Este despunte obedecía a la decisión tomada por la Corte Interamericana de Derechos Humanos $(\mathrm{CIDH})$, que el 9 de enero reconoció los derechos de las parejas de personas del mismo sexo. Fundamentalmente, garantizar a las parejas del mismo sexo todos los derechos existentes en 
la legislación, incluido el derecho al matrimonio, sin discriminación alguna frente a las parejas heterosexuales (CIEP, 2018, pp. 14-15). Después de la resolución la sociedad se dividió en dos bandos contrapuestos, aparentemente irreconciliables.

En décadas anteriores, en Costa Rica, los evangélicos habían tenido una presencia reducida en la Asamblea Legislativa, pero en el periodo reciente (20142018), la visibilidad de estos se debió a que el diputado Fabricio Alvarado, formó parte de un bloque llamado provida, opuesto a legalizar uniones entre personas del mismo sexo, al aborto, la fecundación in vitro y la adopción de niños por parejas no heterosexuales; al mismo tiempo que repartía Biblias en el Congreso (Aranda, 2018). Luego de que la $\mathrm{CIDH}$ ordenara abrir la puerta al matrimonio igualitario, Fabricio Alvarado sostuvo que Costa Rica era un país pro-vida y pro-familia, donde imperaban valores judeocristianos y que no había nada que celebrar sobre la sentencia de la $\mathrm{CIDH}$, ni nada que acatar. Según él, esa decisión no era vinculante, y si lo fuera, entonces, en un gobierno suyo, Costa Rica se saldría de la CIDH, porque no estaba dispuesto a aceptar una agenda LGBTIQ, Pro-Aborto y una ideología de género.

Fabrico Alvarado, obtuvo el primer lugar con una votación de 538.504
(24,99\%), insuficiente para ser presidente (habría una segunda vuelta electoral el 1 de abril), no obstante, el PRC sí obtuvo curules: 14 de las 57 que conforman la Asamblea Legislativa (Tribunal Supremo de Elecciones, 2018, p. 19). De esos catorce diputados, siete se identifican como pastores evangélicos y una persona más es una predicadora (Miranda, 2018). Así el PRC se convirtió en la segunda fuerza política en el Congreso. Fabricio Alvarado, cuando fue diputado, arremetió contra los colectivos LGBTI; realizó giras por el país predicando en iglesias evangélicas y construyendo una credibilidad que el resto de políticos y partidos no lograron.

Su mensaje principal fue la defensa de la familia tradicional y los valores. Este mensaje caló en una sociedad conservadora, donde vastos sectores de la población, se encontraban desencantados de los partidos políticos tradicionales, los cuales cuando fueron gobierno -desde la presidencia de Luis Alberto Monge (1982-1986) en adelante-, aplicaron medidas económicas neoliberales que los golpeó social y económicamente. Estos fueron gobiernos que desmantelaron el estado de bienestar. En ese contexto el fallo de CIDH fue aprovechado por los sectores del fundamentalismo religioso, concentrado en las iglesias neopentecostales portadores de mensajes literales de la Biblia, tanto de condena como de esperanza. 


\section{El fundamentalismo y la agenda moral}

En la mayoría de los casos existe una unión cercana entre las iglesias neopentecostales, algunos sectores conservadores de la iglesia católica romana y los partidos políticos de derecha; estos tres, además de abogar por una sociedad conducida por el mercado, se unen en los procesos electorales, alrededor de la llamada "agenda moral", y se oponen: al aborto, la legalización del consumo de marihuana, la fertilización in vitro, la unión de parejas del mismo sexo y la adopción de hijos por parte de parejas no heterosexuales. Es en este contexto ideológico-moral que surgieron líderes religiosos y políticos como protagonistas (Calderón, 2017).

El obispo brasileño Robson Rodovalho, fundador y presidente de la iglesia neopentecostal Ministerio Sara Nossa Terra, una de las más grandes, con sede en Brasilia, explicó que, a falta de tres meses para la inscripción de candidatos presidenciales, varios políticos le buscaron para construir puentes electorales, y la posición de la iglesia fue la siguiente:

Lo que nosotros entendemos que la sociedad anhela hoy es un candidato que esté comprometido con la cuestión del liberalismo de mercado (...) y al mismo tiempo que sea conservador en los valores, la familia natural, el hombre y la mujer, en la vida, en contra de la cuestión del aborto (Fernandes, M. y Castro, G., 2018)

La agenda política y religiosa del neopentecostalismo no se limita a emitir su mensaje en las calles y en los medios de comunicación, ellos trabajan con el propósito de llegar a puestos de poder político, y desde ahí promover y aprobar leyes que estén de acuerdo con una visión religiosa del mundo y del ser humano, y limitar derechos en áreas como la educación sexual y la educación reproductiva; afectando el respeto y derecho a la diversidad sexual, a la población LGTBI, y a las parejas heterosexuales que no pueden concebir hijos.

Las evidencias de la efectividad y visibilidad de la participación electoral son las redes de feligreses que tienen y, la creciente capacidad económica, comunicacional y logística, que les permiten defender una agenda electoral conservadora funcional al neoliberalismo y contraria a derechos y libertades republicanas (Calderón, Ester, Gómez 2018). Por ejemplo, en Perú, los congresistas evangélicos votaron en bloque -aliados con el fujimorismo- para derogar un decreto del Gobierno que protegía a comunidades vulnerables, entre ellas a la comunidad LGTBI, contra crímenes de odio; o en Colombia, donde los congresistas evangélicos Viviane Morales y Miguel Arrázola lideraron las acciones en contra del Acuerdo de Paz y, en donde un alto número de evangélicos votaron por 
el "NO" debido al "enfoque de género" de algunas partes de los textos acordados entre el gobierno y las FARC, que habría hecho temer a estas personas por el futuro de la familia tradicional (Vargas, 2018).

En Costa Rica las propuestas electorales de Fabricio Alvarado, planteaban una férrea oposición al matrimonio entre personas del mismo sexo, al aborto en cualquier circunstancia, a la fecundación in vitro y a que se impartieran clases de educación sexual en las escuelas porque decían que con ellas se estaba homosexualizando a los niños.

En el Congreso siempre sostuvo posturas fundamentalistas, recurriendo a interpretaciones literales de la Biblia, y expresando mensajes discriminatorios contra las personas no heterosexuales. Impulsó mantener referencias a Dios en la Constitución, se opuso al Estado laico porque, en su opinión, significa promover el ateísmo y abogó por preservar los valores cristianos y la importancia de la familia tradicional.

La reacción del neopentecostalismo hacia la llamada agenda moral la expresan en reuniones eclesiales, en los medios de comunicación (periódicos, revistas, radios, televisión, sitios web, etc.) y en grandes movilizaciones públicas realizadas en varias capitales de América Latina, a las que denominan La marcha por la vida o La marcha por la familia. En todas se visualiza el mismo "enemigo", al que llaman ideología de género, señalándola de falacia que, so pretexto de respetar la diversidad sexual y la igualdad de ambos sexos, destruye la familia, homosexualiza a los niños y niñas, y acaba con las relaciones tradicionales entre hombres y mujeres.

Esta defensa del modelo tradicional de familia no es reciente, otras iglesias evangélicas y la misma Iglesia Católica, siempre tuvieron esa postura, y mostraron reservas y distancias del llamado mundo moderno, no sólo en términos del concepto de familia y sexualidad, sino también en relación a la cultura materialista de consumo. Todavía hoy los sectores evangélicos conservadores, se oponen a la cultura moderna como un todo. Lo que llama la atención es que el neopentecostalismo se adhiere por un lado a la cultura del consumo de la modernidad en un mundo capitalista globalizado y neoliberal y, por otro lado se muestra radical, en contra de los nuevos comportamientos, valores y concepciones acerca de la familia y la diversidad sexual, también pertenecientes a esa modernidad.

Lidiar contra la agenda moral es la principal bandera de movilización del neopentecostalismo, y para eso recurren a un discurso -político y religiosofundamentalista y violento contra las personas que reclaman derechos. Para los neopentecostales, la demanda $-y$ 
otorgamiento- de esos derechos va contra la estabilidad de la familia y las "sanas costumbres". Así, la población LGTBI es víctima de exclusión, odio, discriminación y violencia (psicológica, verbal y física). El neopentecostalismo en general, desde sus iglesias desarrollan prácticas y mensajes homofóbicos (lesbofóbicos, bifóbicos, transfóbicos, etc.) y condenatorios; es un "discurso efectivo por ser difícil de disputar, al estar basado en creencias bíblicas, concebidas como estáticas y ahistóricas establecidas, de una vez y para siempre, por una deidad" (Calderón, Ester, Gómez, 2018).

\section{Una visión crítica de los derechos hu- manos}

¿Cómo abordar una posición obcecada en estos temas sobre derechos humanos? Es una situación, donde en nombre de una creencia (fe) se emiten discursos violentos contra otras personas y se trata de justificar la agresión, exclusión o negación de derechos humanos. En nombre de Dios y en nombre de los derechos humanos se oponen o niegan derechos humanos a otros.

Contrario a lo que sucedía en el pasado con los grupos evangélicos que se "apartaban del mundo", desligándose de cualquier compromiso social y político porque tenían puesta sus esperanzas en "otro mundo" mejor - "más allá de esta tierra”-, el neopentecostalismo incursiona con fuerza en la política, porque para el fundamentalismo no hay distinción entre la religión y otras dimensiones de la vida; para ellos, la religión es el fundamento de la sociedad, no es algo sectorial, ni un aspecto social marginal o una expresión privada de la existencia humana, sino algo que impregna todos los aspectos de la vida individual y social (Arregui, 1994, p. 37).

Visto así, el fundamentalismo neopentecostal se propone restaurar el orden antiguo, en el que las esferas sociales no habían cobrado autonomía. Interpretan su ingreso en el mundo político, no como una participación ciudadana, sino como una imposición. En ese sentido la función de la religión es omniabarcadora de todas las áreas de la vida y del mundo, y con esa perspectiva se sienten con autoridad de segregar, excluir y agredir a otros, negando derechos. Como dice Molina (2018), nadie tiene el derecho de imponer sus creencias religiosas a los demás, porque si esto sucede, entonces se cae en una práctica totalitaria: al creer que su dios y su fe son los únicos verdaderos, entonces lo que sigue es discriminar, perseguir y condenar a quienes no comparten sus creencias. $O$ como señala Gallardo, "por desgracia un porcentaje de gentes estima que puede odiar a los distintos y que ese odio les abrirá la entrada a algún Cielo" (2018, p. 103). Y no solo niegan la humanidad de quienes no comparten sus creencias, sino 
que rechazan todo lo que se oponga a la ortodoxia de su religión, sean instituciones, leyes, tratados internacionales, fallos judiciales, derechos humanos o avances científicos. Para los fundamentalistas, las transformaciones sociales y culturales que afectan su tradición e identidad moral no tienen valor.

Sobre esta situación, el aporte de la teoría crítica de los derechos humanos es indispensable porque ofrece un marco epistemológico contra hegemónico que, cuestiona la racionalidad moderna, el universalismo y el garantismo impuesto sobre los derechos humanos; éstos no deben limitarse a la teoría, sino transcender hacia la praxis socio política e histórica. Los derechos humanos no son instrumentos de poder sino procesos históricos de lucha:

más que derechos "propiamente dichos" son procesos; es decir, el resultado, siempre provisional, de las luchas que los seres humanos ponen en práctica para poder acceder a los bienes necesarios para la vida. Por tanto, nosotros no comenzamos por "los derechos", sino por los "bienes" exigibles para vivir: expresión, confesión religiosa, educación, vivienda, trabajo, medio ambiente, patrimonio histórico artístico (Herrera, 2005, p.3).
La visión tradicional de los derechos humanos se limita al "qué" son los derechos, porque considera que éstos ya han sido conseguidos, y no requieren ser objeto de mayor investigación ni contextualización histórica, social, cultural y política (estos derechos que se dice que ya han sido "conseguidos", no son reales -vivenciales- por ejemplo, para las personas que el neopetencostalismo condena). Por el contrario, los postulados críticos, entienden los derechos humanos, desde el pensamiento no occidentalizado de la razón dominante, y propone perspectivas históricas, liberadoras, emancipadoras y contextualizadas a las distintas realidades de la diversidad de los grupos excluidos; esta perspectiva es sensible a las diversas necesidades de los grupos sociales postergados, excluidos, ninguneados, agredidos o ignorados por la razón hegemónica. Para Herrera (2005), en la visión crítica de derechos humanos, las verdades no nacen de las normas o legislaciones, sino de las prácticas sociales que cada día buscan conseguir acceso a los bienes elementales para vivir, los cuales se han ido obteniendo en el proceso de humanización. Posicionarse epistemológicamente en la perspectiva de las teorías críticas de los derechos humanos, es asumir percepciones y acciones liberadoras, sociohistóricas, emancipadoras y decoloniales de los derechos humanos. Esta perspectiva es ya un espacio espistemológico de inclusión y construcción social orientados a 
las luchas contra hegemónicas del sistema capitalista, imperialista, colonial y patriarcal.

Para el caso que nos ocupa, esa es la perspectiva que debe asumirse porque se trata de poblaciones vulnerables que resisten y luchan contra los poderes del Estado, la razón dominante y el poder religioso. Sin la inclusión de estas luchas al reconocimiento formal de los derechos, éstos se entenderán de forma equívoca y reducida, y se pensará que la ejecución jurídica del marco legal de los derechos humanos, equivaldrá a la protección, garantía y disfrute de los mismos (Gándara, 2014).

Desde las distintas raíces sociales, dolores y resistencias que enfrentan las poblaciones minoritarias excluidas ante el abuso del poder (político, económico, religioso, jurídico, etc.), dentro del sistema capitalista, cristiano, discriminatorio, patriarcal e imperialista, salta a la luz, los vacíos, limitaciones e intenciones del pensamiento hegemónico sobre los derechos humanos; es un discurso anclado en las relaciones de poder del colonialismo occidental, por lo tanto, exige repolitizar la praxis de los derechos humanos entendiéndolos como luchas que aseguren condiciones de vida digna para todas las personas (Gándara, 2014). Ante la necesidad de lograr los bienes vitales que aseguren la vida y dignidad de los seres humanos, se gestan procesos de lucha por los derechos humanos; y va a depender de las estructuras y poderes económicos, socioculturales y políticos, con sus respectivas instituciones, para que esos bienes vitales sean más accesibles para algunos grupos que para otros; y son las poblaciones referidas en este trabajo, las que tienen mayores obstáculos para conseguir esos derechos.

\section{Una visión desde las epistemologías del sur}

Como sabemos, el sur al que estas epistemologías hacen referencia, no es geográfico; el sur es una metáfora del sufrimiento humano injusto, es el sur anti-imperial, anti-colonial, anti-patriarcal y anti-capitalista, (también hay un Sur dentro del Norte). El Sur son los que sufren las injusticias del imperialismo, el colonialismo, el patriarcado y el capitalismo. Las epistemologías del sur, proponen pensar una situación como estas, desde la perspectiva de los que han sufrido sistemáticamente las injusticias. Para esta perspectiva, la comprensión del mundo es mucho más amplia que la comprensión occidental del mundo. Por eso hay que mirar la experiencia del mundo en toda su amplitud, en toda su riqueza, porque la experiencia del mundo es infinita y, no hay ninguna teoría general que la pueda cubrir totalmente, que pueda contabilizar toda esta experiencia.

Las espistemologías del sur son un reclamo por la validez de otros conocimientos más allá del conocimiento científico eurocéntrico; de no ser así, entonces 
estamos ante una injusticia cognitiva. El conocimiento científico se presenta como exhaustivo, exclusiva y completo, es un conocimiento dominante, pero es parcial, selectivo y excluyente. Para que exista una justicia social global tiene que haber una justicia cognitiva global. Aquí hay un problema epistemológico porque existe destrucción de conocimientos alternativos; sin esos conocimientos, el conocimiento hegemónico no logra ser hegemónico. La gran creación científica de nuestro tiempo está basada en un epistemicidio: en la muerte de otros conocimientos. Pero eso que no existe, es una inexistencia de producción sociohistórica, realizada desde la monocultura racional:

Hay producción de no existencia siempre que una entidad dada es descalificada y tornada invisible, ininteligible o descartable de un modo irreversible. Lo que une a las diferentes lógicas de producción de no existencia es que todas sean manifestaciones de la misma monocultura racional (Santos, 2009, p.109).

Si se quiere ver el mundo con otros ojos, con otras perspectivas, entonces, esos conocimientos deben ser rescatados en la medida de lo posible; de lo contrario -como hemos visto antes en el caso del proceder del neopentecostalismo-, el odio se normaliza, el desprecio se acepta, la discriminación se legaliza, el horror se banaliza, la injusticia se minimiza, y nos acostumbramos a ese "único" mundo, como si fuera algo tan natural que, no merecemos un mundo más justo y más humano. Por eso tenemos que aceptar, vivir y crecer como seres humanos con la pluralidad y la diversidad; estas deben promoverse y celebrarse, no sufrirse, se debe vivir con la celebración de la riqueza plural de la humanidad. De manera que luchar políticamente significa también luchar epistemológicamente por otras formas de conocimiento, por un conocimiento que nazca desde las luchas, como lo propone la teoría crítica de los derechos humanos.

La ciencia es importante, pero no es la única manera válida de conocer el mundo, hay otros maneras de conocer el mundo que pueden ser más importantes para otros objetivos de la vida. Ante la evidencia de que el mundo puede ser conocido por otras formas y no sólo por la ciencia, entonces, se produce un sentimiento de agotamiento del pensamiento eurocéntrico, y a eso se agrega que Europa con su historia y práctica colonialista se incapacitó para aprender de las experiencias del mundo. Pero el colonialismo no terminó con la independencia y con el fin del colonialismo político como registran los libros de la historia oficial con fechas y personajes, sino por el contrario continuó hasta nuestros días con otras formas de colonialismo, por ejemplo 
con la discriminación (discriminación que muchas veces se hace en nombre de Dios o de los derechos humanos). Cuando se descalifica al otro por su supuesta "inferioridad", ahí está presente -en las vivencias cotidianas y públicas- el colonialismo. Sin embargo, esto ha sido naturalizado, y se ignora que el colonialismo empobrece -y deshumaniza- tanto al colonizado, como al colonizador.

A nivel de las ciencias sociales y de las diferentes áreas del conocimiento, las epistemologías del sur analizan, desentrañan y develan las formas de exclusión radical que contienen las teorías sobre la ciudadanía, los derechos humanos, la democracia, la participación, etc.; son teorías producidas por la ciencia racionalista moderna desde las sociedades capitalistas y con perspectivas colonialistas. Al respecto señala Santos que, "desde el punto de vista epistemológico, la sociedad capitalista moderna se caracteriza por favorecer las prácticas en las cuales predominan las formas de conocimiento científico" (2009, p. 114).

Si la comprensión del mundo es mucho más amplia que la promovida y realizada desde el racionalismo eurocéntrico y cristiano, entonces es necesario ingresar a otros conocimientos y admitirlos como tales; ellos nos van a dar un gran abanico y diversidad de conocimientos; a esto las epistemologías del sur le llama la "ecología de saberes". De esos diferentes saberes no se puede determinar su validez en términos generales abstractos, porque ellos valen de acuerdo con la pragmática de la vida. Eso significa que no hay una sola forma de ignorancia, hay varias formas de ignorancia. Para llegar a la ecología de saberes se necesita de dos procedimientos: la sociología de las ausencias y la sociología de las emergencias. Lo que se busca es rescatar realidades que no existen, que fueron declaradas como no existentes. La sociología de las ausencias lograr mostrar que la ciencia moderna produce como no existente muchas partes de la realidad; por eso la propuesta de la sociología de las ausencias es sustituir la monocultura por la ecología. Y cuando se rescata esas otras partes de la realidad, se amplifica los sentidos y se transforma en emergencia, es decir, asume el sentido del desarrollo alternativo.

De acuerdo con Santos, las espistemologías del sur señalan cinco lógicas de producción de no existencia, una de ella es la "clasificación social" que, "se asienta en la nonocultura de la naturalización de las diferencias. Consiste en la distribución de las poblaciones por categorías que naturalizan jerarquías. La clasificación racial y la clasificación sexual son las manifestaciones más señaladas de esta lógica” (2009, p.110).

Dentro de esta lógica de la clasificación social -clasificación que descalifica a otros- se encuentran esos colectivos humanos, a quienes el fundamentalismo 
neopentecostal ataca, desde una visión cristiana, patriarcal, jerárquica, "racional", "natural" y reducida de mundo; los clasifica, y los niega, los considera no válidos, equivocados, errados, depravados, perdidos y pecadores, ellos son: las poblaciones LGTBI, la mujeres que reclaman el derecho al aborto, la parejas que requieren y abogan por la fecundación in vitro, las parejas no heterosexuales que quieren adoptar hijos, entre otros. Como dice Santos, si bien todas las lógicas que producen ausencias descalifican las prácticas y a sus agentes, la lógica de la clasificación social prioriza la descalificación de los agentes (2009, p. 119), léase en nuestro caso a los colectivos sociales antes mencionados. Un hecho ilustrativo de esa visión fundamentalista sobre las personas homosexuales, puede verse en una entrevista realizada a un político evangélico de Costa Rica presidente en ese entonces de la comisión de Derechos Humanos de la Asamblea Legislativa, donde pretende desde su visión cristiana, justificar la discriminación hacia las personas homosexuales (Internetdanny, 2012). Sucede que el colonialismo del poder cristiano, capitalista, moderno y occidental identifica diferencia con desigualdad, y determina quién es igual y quién es diferente, y el diferente es invisibilizado, negado, ninguneado o excluido.

Ante esta situación -desentrañada por la sociología de las ausencias-, las epistemologías del sur, desde la diversidad de los saberes, proponen la ecología de los reconocimientos:

La sociología de las ausencias se confronta con la colonialidad, procurando una nueva articulación entre el principio de igualdad y el principio de diferencia y abriendo espacio para la posibilidad de diferencias iguales -una ecología de diferencias hechas a partir de reconocimientos recíprocos (Santos, 2009, p. 120).

En América Latina en los últimos tres lustros los movimientos indígenas, feministas, defensores de los derechos humanos, campesinos, afrodescendientes, colectivos LGTBI entre otros, desde sus particularidades, han estado al frente en la disputa por una ecología de los reconocimientos; son batallas por la emancipación social, contra toda forma de discriminación, exclusión, opresión y dominación. Sus luchas son también por el "reconocimiento de derechos colectivos; por la defensa y promoción de marcos normativos alternativos o tradicionales, de formas comunitarias de producción de medios de subsistencia o de resolución de conflictos, etc. (Santos, 2009, p. 121).

\section{Algunas reflexiones para no concluir}

El fundamentalismo neopentecostal es una expresión socio cultural, socio religiosa y socio política que está presente 
en la mayoría de los países de América Latina; si bien es cierto que en algunos países tiene mayor representación y acción que en otros, sin embargo, en todos aparece con proyección de crecimiento y, mayor inserción en los asuntos públicos. Ya no se puede negar y menos aún menospreciar -como se hacía antes desde la "academia" y la razón - a los grupos religiosos y al papel que vienen ejerciendo en la sociedad.

A diferencia del pentecostalismo tradicional, el neopentecostalismo posee ingentes recursos logísticos, materiales, financieros, tecnológicos y mediáticos; y su propósito no es "salvar las almas" sino "salvar la naciones" vía los partidos confesionales en el poder. El neopentecostalismo no tiene la visión puesta en un futuro trascendente a la historia, sino en el presente; no le interesa el "más allá", sino el "aquí y el ahora"; no está dedicado a los menesteres celestiales, sino a los terrenales y materiales, y convive sin animadversión con la vorágine consumista que ofrece la modernidad. Porque no tiene la mirada puesta en los cielos, sino en la tierra, es que le interesa el poder político.

Si el neopentecostalismo siguiera la tradición pentecostal de "apartarse" del mundo, rechazar la política -porque responde a intereses materiales-, abocarse al proselitismo para la salvación de las almas y respetar las creencias de las demás personas, no sería motivo de preocupación; pero vemos que los intereses del neopentecostalismo son más extraeclesiales que intraeclesiales, por eso se presentan como los restauradores del mundo, y quieren abarcarlo todo y a todos; es una especie de totalitarismo religioso que busca permear y copar todas las áreas de la vida, y por eso genera preocupación.

Lo grave del neopentecostalismo consiste en que porta una creencia y un mensaje frontal contra los derechos humanos que afecta a vastos sectores sociales: las mujeres, las personas que necesitan de la fertilización in vitro, la parejas no heterosexuales que quieren adoptar niños, las parejas no heterosexuales que desean la unión civil, las mujeres que quieren decidir sobre sus cuerpos en diversas circunstancias pero la ilegalidad del aborto se los impide, etc. Es un mensaje sensible que cala con facilidad en la gente sencilla, las cuales se convierten en seguidores y defensores de lo que los líderes predican; por ejemplo, defienden el modelo de familia tradicional como modelo único y verdadero, sin exponer razones o argumentos; y desde esa visión agreden a quienes no piensan como ellos o realizan actividades donde emiten discursos de odio, irrespeto e intolerancia hacia las personas que son "diferentes".

A partir de la interpretación literal que hacen de la Biblia, asumen una visión maniquea del mundo, y pretenden 
legislar e imponer, lo que debe ser correcto e incorrecto para todos; el neopentecostalismo quiere hacer del mundo una iglesia neopentecostal.

No es exagerado decir que el neopentecostalismo es un nuevo "fantasma" (con cuerpo, necesidades y pretensiones bien definidos) que recorre el continente latinoamericano desde hace dos décadas y, lo hace con evidentes objetivos políticos; hasta ahora ha logrado incidir en varios países, con decisiones y legislaciones públicas, sobre casos de derechos humanos, pero no satisfecho con eso, aspira a más: quiere tener el control de los primeros poderes del Estado. De modo que estudiar el fundamentalismo religioso es acercarse a un hecho histórico, social, cultural y político, no es un asunto místico, casual o abstracto, tampoco se trata de un fenómeno menor ni pasajero, por eso tiene la atención de la sociología de la religión, la antropología sociocultural, los derechos humanos y los estudios latinoamericanos; y los acercamientos que se hagan a este fenómeno, deben tomar en cuenta las perspectivas propuestas por las teorías críticas de los derechos humanos y las epistemologías del sur, porque lo que se busca es visibilizar y reconocer las luchas de las poblaciones mencionadas en la conquista de sus derecho, hacia un mundo anticolonial, antipatriarcal y antimperial.

\section{Referencias bibliográficas}

Aranda, L. (2018). Política y religión en Costa Rica, ¿de vuelta al siglo XIX? Recuperado de http:// www.elfinanciero.com.mx/opinion/lourdes-aranda/politica-yreligion-en-costa-rica-de-vuelta-alsiglo-xix

Arregui, J. (1994). El fundamentalismo y los fundamentos de la sociedad. La inevitable cadencia atea del fundamentalismo moderno. Recuperado de http://institucional.us.es/revistas/themata/12/02\%20arregui.pdf

Assmann, H. (1988). La Iglesia Electrónica y su impacto en América Latina. San José de Costa Rica: DEI.

Bastian, J. (1999). Los nuevos partidos políticos confesionales y su relación con el Estado en América Latina. Estudios sociológicos, Vol 17, n. 49, México, 1999, pp, 153 - 173.

Bedinelli, T. Marcos, A. y Lafuente, J. (2018). La fe evangélica abraza las urnas en América Latina. Recuperado de https://novusdiesest.blogspot.com/2018/05/ la-fe-evangelica-abraza-las-urnasen.html

Calderón, J. (2017). Iglesias evangélicas y el poder conservador en Latinoamérica. Recuperado de http://www.celag.org/iglesias-evangelicas-poder-conservador-latinoamerica/ 
Calderón, J., Ester, B. y Gómez, A. (2018). La re-espiritualización de la política. Recuperado de https://www.celag.org/la-re-espiritualizacion-la-politica/

CIEP-Universidad de Costa Rica. (2018). Informe de resultados de la encuesta de opinión sociopolítica realizada en enero de 2018 . Recuperado de https://ciep. ucr.ac.cr/images/INFORMESUOP/EncuestaEnero/Informe-encuesta-ENERO-2018.pdf

Della, R. (2018). La 'ola Bolsonaro' lleva a Brasil a su Congreso más conservador desde el fin de la dictadura. Recuperado de https://elpais.com/internacional/2018/10/17/america/1539737969_136400.html

de la Torre, R. y Gutiérrez, C. (Coord.). (2007). Atlas de la diversidade religiosa en México. Jalisco: El Colegio de Jalisco.

Fernandes, M. y Castro, G. (2018). Voto dos evangélicos terá peso inédito nas eleições de 2018. Recuperado de https://www.huffpostbrasil.com/2018/01/12/voto-dosevangelicos-tera-peso-inedito-naseleicoes-de-2018_a_23332289/

Gallardo, H. (2018). Los bárbaros ya estaban aquí. Elecciones 2018. San José: Editorial Arlekín.
Gandara, M. (2014). Repensando los derechos humanos desde las luchas. Recuperado de file://C:/ Users/Abner/AppData/Local/ Temp/Repensando_los_derechos_humanos_desde_la.pdf

Herrera, J. (2005). La complejidad de los Derechos Humanos, bases teóricos para una definición crítica. Recuperado de http:// www.egov.ufsc.br/portal/sites/ default/files/anexos/33315. 42530-1-PB.pdf

Internetdanny. (7 junio de 2012). Entrevista Justo Orozco- Pilar Cisneros Telenoticias parte 1 [video]. Recuperado de https://www. youtube.com/watch?v=78GXgrqr8Xc

Lissardy, G. (2018). "La fuerza política más nueva": cómo los evangélicos emergen en el mapa de poder en América Latina. Recuperado de https://www.bbc.com/ mundo/noticias-america-latina-43706779

López, D. (2004). La seducción del poder. Los evangélicos y la política en el Perú de los noventa. Lima: Edicioes Puma.

Mallimaci, F. (dir.) (2013). Atlas de las creencias religiosas en la Argentina. Buenos Aires: Biblos.

Míguez, J. (1995). Rostros del protestantismo latinoamericano. Buenos Aires: Nueva Creación. 
Míguez, D. (2001). El Protestantismo Popular en la Argentina. Las Lógicas de Expansión del Pentecostalismo Durante el Siglo XX. Recuperado de http:// www.diversidadreligiosa.com.ar/ wp-content/uploads/2013/04/ Miguez_Protestantismo_Popular.pdf

Miranda, H. (2018). Conformación de nueva Asamblea Legislativa. Mitad de diputados de Restauración Nacional son pastores evangélicos. Recuperado de https:// semanariouniversidad.com/ pais/mitad-diputados-restauracion-nacional-pastores-evangeli$\cos /$

Molina, I. (2018). La indispensable separación que debe haber entre religión y política. Recuperado de https://www.nacion.com/ opinion/columnistas/la-indispensable-separacion-que-debe-haber-entre/ELFZ65G3DZAVPO46HRCCRBBPMU/story/

Parrode, A. (2014). Iris Rezende completa 81 anos; reveja grandes momentos da carreira do ex-governador. Jornal Opção. Recuperado de https://www.jornalopcao.com.br/ultimas-noticias/ iris-rezende-completa-81-anos-reveja-grandes-momentos-da-carreira-do-ex-governador-24251/
Piedra, A. (editor). (2006). Haciendo teología en América Latina. Juan Stam: un teólogo del camino. Vol. 1. San José, Costa Rica: SEBILA. Plumas Atómicas. (2017). ¿Qué es el Partido Encuentro Social y por qué no entendemos su alianza con Morena? Recuperado de https://plumasatomicas.com/ noticias/resultados-elecciones/ encuentro-social-historia-evangelicos/

Romero, C. et al. (2003). Atlas da diversidade religiosa e indicadores sociais no Brasil. Rio de Janeiro: Ed, Loyola.

Royo, J. (2018). Bolsonaro: el candidato racista, homófobo y machista de Brasil. Recuperado de http://www.elmundo.es/loc/ celebrities/2018/09/29/5bae3d88268e3e995f8b4662.html

Saccone, V. (2016). Los evangélicos se lanzan a la conquista del poder en Brasil. Recuperado de https://www.elconfidencial.com/mundo/2016-11-10/ brasil-evangelicos-america-latina-religion-rio-de-janeiro-alcalde_1287360/

Saccone, V. (2018). El respaldo de los cristianos a Jair Bolsonaro. Recuperado de https://www.france24.com/es/20181021-elecciones-brasil-iglesia-evangelica-bolsonaro 
Sánchez, E. (2018). Evangélicos y protestantes: el nuevo poder político en América Latina. Recuperado de http://laopinion-digital. com/opinion/evangelicos-protestantes-nuevo-poder-politico-america-latina/08-02-2018

Santos, B. (2009). Una epistemología del sur: la reinvención del conocimiento y la emancipación social. México: Siglo XXI.

Tamayo, J. (2009). Fundamentalismos y diálogo entre religiones. Madrid: Editorial TROTTA.

Tribunal Supremo de Elecciones. (2018). Cómputo de votos y declaratorias de elección 2018. Recuperado de http://www.tse. go.cr/pdf/elecciones/computovotos_febrero_abril_2018.pdf
Vargas, A. (2018). Los evangélicos y las urnas. Recuperado de http:// www.latercera.com/reportajes/ noticia/columna-alvaro-vargas-llosa-los-evangelicos-las-urnas/77854/

Watson, K. (29 de octubre, 2018). Jair Bolsonaro gana en Brasil: los 5 grupos que le dieron el triunfo al polémico presidente electo. Recuperado de https://www. bbc.com/mundo/noticias-america-latina-46018820 